\author{
United Nations Educational Scientific and Cultural Organization \\ and \\ International Atomic Energy Agency
}

THE ABDUS SALAM INTERNATIONAL CENTRE FOR THEORETICAL PHYSICS

\title{
MODELING OF HEAT AND MASS TRANSFER IN LATERITIC BUILDING ENVELOPES
}

\author{
Pierre Meukam ${ }^{1}$ \\ Laboratoire d'Énergétique, École Nationale Supérieure Polytechnique, \\ P.O. Box 8390, Yaoundé, Cameroon \\ and
}

The Abdus Salam International Centre for Theoretical Physics, Trieste, Italy.

\begin{abstract}
The aim of the present work is to investigate the behavior of building envelopes made of local lateritic soil bricks subjected to different climatic conditions. The analysis is developed for the prediction of the temperature, relative humidity and water content behavior within the walls. The building envelopes studied in this work consist of lateritic soil bricks with incorporation of natural pozzolan or sawdust in order to obtain small thermal conductivity and low-density materials, and limit the heat transfer between the atmospheric climate and the inside environment. In order to describe coupled heat and moisture transfer in wet porous materials, the coupled equations were solved by the introduction of diffusion coefficients. A numerical model HMtrans, developed for prediction of heat and moisture transfer in multi-layered building components, was used to simulate the temperature, water content and relative humidity profiles within the building envelopes. The results allow the prediction of the duration of the exposed building walls to the local weather conditions. They show that for any of three climatic conditions considered, relative humidity and water content do not exceed $87 \%$ and $5 \%$ respectively. There is therefore minimum possibility of water condensation in the materials studied. The durability of building envelopes made of lateritic soil bricks with incorporation of natural pozzolan or sawdust is not strongly affected by the climatic conditions in tropical and equatorial regions.
\end{abstract}

\author{
MIRAMARE - TRIESTE
}

October 2004

\footnotetext{
${ }^{1}$ Regular Associate of ICTP. pierrre_meukam@yahoo.fr
} 


\begin{tabular}{|llll|}
\hline Nomenclature & \multicolumn{3}{l|}{ Greek letters } \\
$\mathrm{C}$ & Material specific heat $\left(\mathrm{J} \mathrm{kg}^{-1} \cdot{ }^{\circ} \mathrm{C}^{-1}\right)$ & $\rho$ & Material density $\left(\mathrm{kg} \mathrm{m}^{-3}\right)$ \\
$\mathrm{D}$ & Water diffusivity & $\rho_{\mathrm{w}}$ & Liquid water density $\left(\mathrm{kg} \mathrm{m}^{-3}\right)$ \\
$\mathrm{RH}$ & Relative humidity $(\%)$ & $\phi$ & Volumetric water content $(\%)$ \\
$\mathrm{k}$ & Material thermal conductivity $\left(\mathrm{W} \mathrm{m}^{-1} \mathrm{C}^{-1}\right)$ & $\gamma$ & Latent heat of water $\left(\mathrm{J} \cdot \mathrm{kg}^{-1}\right)$ \\
$\mathrm{T}$ & Temperature $\left({ }^{\circ} \mathrm{C}\right)$ & $\mu$ & chemical potential \\
$\mathrm{t}$ & Time $(\mathrm{s})$ & \multicolumn{2}{l}{ Subscripts } \\
$\mathrm{P}_{\mathrm{vs}}$ & Saturation vapour pressure & $\mathrm{T}$ & Temperature gradient \\
$\mathrm{x}$ & Distance $(\mathrm{m})$ & $\mathrm{G}$ & Gas phase \\
$\mathrm{y}$ & Distance $(\mathrm{m})$ & $\phi$ & Water content gradient \\
\hline
\end{tabular}

\section{Introduction}

Construction materials made from recycled sources are becoming widely available and can minimize a new building's impact on the environment. For home and small commercial buildings, construction using inexpensive natural materials, such as earth blocks, is also becoming more commonplace in many regions in Africa. In terms of the energy performance of a building, the materials used in the building envelope are the most crucial, since the building envelope defines how the building interacts with the external environment. The development of heat transfer analysis for the prediction of the thermal behavior of structural walls is a problem of a fundamental concern in a broad range of engineering applications. The envelope of a building protects the indoor environment from outside. Building components like walls, in service conditions, are subjected to variable climatic conditions, which are different between their exposed sides. The building envelopes are exposed to two different climates, which can create a hygrothermal transfer within their components. Many building walls are made of hygroscopic materials. The building envelope may have moisture sources, people and their activities in case of tanks in attics, water evaporation from the ground if it is not covered, plumbing leaks in wall cavities, etc. It will also have air exchanges into and out of the building volume.

In porous building materials, water can be in liquid or gaseous phase. The phase changes and the migration of moisture are always linked to heat transfer. The moisture behavior of exposed building elements has a predominant influence on their durability because water is often the major reason for damage and decay. Therefore, the vapour and liquid transport properties of porous materials are of great practical importance. There are now many numerical models that are capable of describing heat and moisture transfer within the building envelope [1-2]. Generally, these models developed for combined heat and moisture transport needed for calculations of the hygrothermal behavior of composite building construction, takes advantage of the similarities between the governing equations for transient transfer of heat, vapour and liquid. Experimental and numerical studies have been carried out in Building Research Institute (BRI) Japan, on simultaneous heat and mass transfers in building components [3]. For modeling of hydric behavior, a computer program was used and permitted to determine time-dependent distributions of temperature and moisture content in multilayer structures during wetting and drying. A fully coupled model for simulating heat and mass transfer in deformable porous materials regarding also phase change has been presented by Gawin [4]. 
A frequency-domain regression has been developed for transient heat flow calculation of multilayer constructions [5]. It was used to perform transient analysis of heat flow through building constructions, including the computation of response factors and conduction transfer coefficients.

Nevertheless, there is a number of building envelopes in developing countries whose behavior is unknown. Particularly in Africa, most of rural buildings are made from earth blocks. The knowledge of the properties of this building material is necessary to study the heat transfer across the walls. An experimental study has been carried out in order to determine the thermo physical properties of lateritic soil bricks in Cameroon [6]. This study showed that the incorporation of natural pozzolan or sawdust, in lateritic soil bricks, is to decrease their thermal conductivity. They can consequently be used as insulating building materials. The application of the computer program HMTrans, developed by Watanabe [7], was used to simulate the behavior of the lateritic soil bricks utilized as building envelopes. This program permitted the prediction of the distribution of temperature; humidity and moisture content in these components exposed to three different variable climatic conditions (wet equatorial climate, wet tropical climate and dried tropical climate).

\section{The mathematical formulation}

Lateritic soil brick used in this study, as building envelope is a porous material. It contains water in liquid or gaseous phases. Since outdoor and inside surfaces are at different temperatures, conduction transfer occurs within the wall materials and heat transfer accompanies any change of phase. The mathematical formulation is based on heat and moisture balance in the process of moisture migration.

\section{- Assumptions}

- There is no chemical reaction, which occurs in the migration process.

- Thermal properties (i.e. $\mathrm{k}, \rho$ and $\mathrm{Cp}$ ) of materials are considered to be constant.

Within the building envelope, taking the above assumptions into account, heat and moisture transfer are governed by the following equations.

\section{- Mass conservation}

The moisture content change of the cell in a unit time is determined by the diffusion of moisture in two directions as shown in equation (1).

$$
\rho_{w} \frac{\partial \phi}{\partial t}=\frac{\partial}{\partial x}\left[D_{\phi} \frac{\partial \phi}{\partial x}+D_{T} \frac{\partial T}{\partial x}\right]+\frac{\partial}{\partial y}\left[D_{\phi} \frac{\partial \phi}{\partial y}+D_{T} \frac{\partial T}{\partial y}\right]
$$

where $\mathrm{D}_{\phi}$ and $\mathrm{D}_{\mathrm{T}}$ are hydric diffusivity and thermal diffusivity respectively.

\section{- Energy conservation}

The moisture migration coupled with heat transfer and the temperature change of the cell in a unit time is determined by heat lost or gained. It is due to heat conductance and potential heat in migrated water and is expressed by equation (2). 


$$
\rho \mathrm{c} \frac{\partial \mathrm{T}}{\partial \mathrm{t}}=\frac{\partial}{\partial \mathrm{x}}\left[\left(\mathrm{k}+\gamma \mathrm{D}_{\mathrm{TG}}\right) \frac{\partial \mathrm{T}}{\partial \mathrm{x}}+\gamma \mathrm{D}_{\varphi \mathrm{G}} \frac{\partial \varphi}{\partial \mathrm{x}}\right]+\frac{\partial}{\partial \mathrm{y}}\left[\left(\mathrm{k}+\gamma \mathrm{D}_{\mathrm{TG}}\right) \frac{\partial \mathrm{T}}{\partial \mathrm{y}}+\gamma \mathrm{D}_{\varphi \mathrm{G}} \frac{\partial \varphi}{\partial \mathrm{y}}\right]
$$

where $\mathrm{D}_{T}, \mathrm{D}_{\mathrm{G}}, \mathrm{D}_{\mathrm{TG}}$ and $\mathrm{D}_{\phi \mathrm{G}}$ are respectively thermal, hydric, thermal in gaseous phase and hydric in gaseous phase diffusivities of water.

\section{- Boundary conditions: sorption isotherm}

The local moisture content is determined by the sorption isotherm of the materials as defined by relation (3).

$$
\phi=F(h, t) \cong F(h)
$$

Equations (1) and (2) cannot be applied to non-hygroscopic materials. In the presence of surfaces in contact with no hygroscopic materials or air layers, (4) and (5) should replace equations (1) and (2).

$$
\begin{aligned}
& -\left(\mathrm{D} \phi \frac{\partial \phi}{\partial \mathrm{x}}+\mathrm{D}_{\mathrm{T}} \frac{\partial \mathrm{T}}{\partial \mathrm{x}}\right) \mathrm{s}=\alpha^{\prime}\left(\mathrm{X}_{\mathrm{n}}-\mathrm{X}_{\mathrm{s}}\right) \\
& \left\{\left(\mathrm{k}+\gamma \mathrm{D}_{\mathrm{Tg}}\right) \frac{\partial \mathrm{T}}{\partial \mathrm{x}}+\gamma \mathrm{D}_{\phi g} \frac{\partial \phi}{\partial \mathrm{x}}\right\} \mathrm{s}=\mathrm{k}^{\prime}\left(\mathrm{T}_{\mathrm{N}}-\mathrm{T}_{\mathrm{S}}\right)+\gamma \mathrm{k}^{\prime}\left(\mathrm{X}_{\mathrm{N}}-\mathrm{X}_{\mathrm{S}}\right)
\end{aligned}
$$

where

$\mathrm{k}$ : thermal conductivity of the non-hygroscopic material

$\mathrm{k}$ ': hydric conductivity of non-hygroscopic material,

$\mathrm{X}$ : absolute humidity

S: surface of the hygroscopic material

$\mathrm{N}$ : surface of the non-hygroscopic material

The boundary conditions are also replaced by $\phi=\mathrm{f}(\mathrm{X}, \mathrm{T})$.

In the present model, the following assumptions were considered in the hygroscopic regions.

$$
\begin{aligned}
& \mathrm{D}_{\phi}=\mathrm{D}_{\phi \mathrm{g}}=\Pi \mathrm{P}_{\mathrm{sv}}\left(\frac{\partial \mathrm{h}}{\partial \phi}\right)_{\mathrm{T}} \\
& \mathrm{D}_{\mathrm{T}}=\mathrm{D}_{\mathrm{Tg}}=\Pi \mathrm{RH} \frac{\partial \mathrm{P}_{\mathrm{sv}}}{\partial \mathrm{T}}
\end{aligned}
$$

where $\Pi$ is the vapour permeability, $P_{s v}$ is the saturation vapour pressure and $R H$ the relative humidity.

Isotherm sorption relation (3) gives the local water content as a function of relative humidity. It is used to determine graphically the water content at saturation corresponding to a relative humidity of about $100 \%$. It is obtained experimentally for each building envelope component.

Equations (1) and (2) cannot be applied to both liquid and gaseous phases. In the present model, water content $\phi$ is replaced by water chemical potential $\mu$. In fact, the latter is continuous even 
if there is a phase change without chemical reaction. When $\phi$ is replaced by water chemical potential $\mu$, equations (1) and (2) become:

$$
\begin{aligned}
& E \frac{\partial \mu}{\partial t}=\frac{\partial}{\partial x}\left(A(x, y) \frac{\partial \mu}{\partial x}+B(x, y) \frac{\partial T}{\partial x}\right)+\frac{\partial}{\partial y}\left(A(x, y) \frac{\partial \mu}{\partial y}+B(x, y) \frac{\partial T}{\partial y}\right) \\
& F \frac{\partial T}{\partial t}=\frac{\partial}{\partial x}\left(C(x, y) \frac{\partial T}{\partial x}+D(x, y) \frac{\partial \mu}{\partial x}\right)+\frac{\partial}{\partial y}\left(C(x, y) \frac{\partial T}{\partial y}+D(x, y) \frac{\partial \mu}{\partial y}\right)
\end{aligned}
$$

where,

$$
\mathrm{E}=\rho_{\mathrm{w}} \frac{\partial \varphi}{\partial \mu}
$$

$\mathrm{F}=\rho \mathrm{c}$

A $(x, y):$ moisture diffusivity due to chemical potential gradient $\left(\prod_{\mu}\right)$,

$\mathrm{B}(\mathrm{x}, \mathrm{y}):$ moisture diffusivity due to temperature gradient $\left(\prod_{\mathrm{T}}\right)$,

$\mathrm{C}=\mathrm{k}+\gamma \prod_{\mathrm{TG}}$,

$\mathrm{D}=\gamma \prod_{\mu \mathrm{G}}$

By introducing the chemical potential, the coupled heat and moisture transfer was thus simplified into two partial differential equations where temperature and water chemical potential are used as driving potentials for both heat and moisture transfer.

- relative humidity is converted inversely as $\mathrm{RH}=\exp \left(\mu / \mathrm{R}_{\mathrm{v}} \mathrm{T}\right)$,

- moisture content is obtained through sorption isotherms (equations of state) as a function of RH,

- vapour pressure is obtained through saturation vapour pressure curves and relative humidity as $P_{v}$

$=$ RH. $P_{\text {vsat }}$

\section{The description of the reference walls}

Various standard building envelope designs are currently employed in construction. A wide range of composite walls, making extensive use of heavier materials like masonry, concrete and bricks, are broadly employed locally, the use of which is mainly imposed by regulation and prevailing conditions. The outdoor conditions are dependent on the meteorological parameters. The inside temperature and humidity are often chosen to satisfy the inhabitant's comfort. For the purpose of the present investigation, three building envelope designs were selected on the basis of their different thermal characteristics. One of them is broadly employed for construction in rural areas in Africa. The first structure corresponds to a cement stabilized lateritic soil wall of uniform thermo physical properties, which is mainly employed in building frame. The second building envelope studied was lateritic soil brick with incorporation of natural pozzolan in order to have more insulator material. The third envelope is constituted with lateritic soil with addition of sawdust. Three types of wall are considered for any structure.

- Single wall with only one of the above materials;

- Composite wall with one of the three materials and a layer plaster on the inner surface;

- Composite wall with one of the three materials and two similar layers of plaster at both the inner and the outer surfaces. 
Although both walls are supposed to be $0.15 \mathrm{~m}$ thick and the plaster layer $0.06 \mathrm{~m}$ thick, their design and their thermo physical properties differ.

\section{The development of numerical model}

Equations (8) and (9) were solved simultaneously to determine chemical potential $\mu$ and temperature $T$. When temperature $T$ and chemical potential $\mu$ are known, relative humidity is calculated using the following Arrhénius law:

$$
\text { R.H. }=\mathrm{e}^{\left(\mu / \mathrm{R}_{\mathrm{v}} \cdot \mathrm{T}\right)}
$$

where $\mathrm{Rv}$ is a water vapour constant.

Due to the daily changes of meteorological parameters, the problem has been solved in each day and the calculations were extended during a year.

Numerical calculations were carried out using finite difference approximation. The solution is obtained by an accelerated convergence method. The building wall consists of one, two or three layers including the surface films at both sides and can be regarded as one-dimensional multilayer plane constructions. Each layer is homogeneous and has constant thermal properties (i.e. k, $\rho$, and Cp). For the application of this model, the composite wall was subdivided into sublayer sections of uniform thermophysical properties and thickness $0.015 \mathrm{~m}$. A computer program HMtrans [7], was used. HMTrans was written in Fortran to prevent water condensation in building envelopes in Japanese town climates. It is adaptable to the climates studied in this work. For each material, the knowledge of the following parameters is essential.

- Thermal properties (density, thermal conductivity and specific heat)

- Vapour permeability.

- Water content at saturation

- Width $\mathrm{x}$ and height $\mathrm{y}$ of the wall.

For the calculations, material properties were determined experimentally in the Laboratory of Energetic at ENSP, Yaoundé (Cameroon). The results are presented in Table 1.

Table 1: Physical properties of the materials used in the study

\begin{tabular}{|c|c|c|c|c|c|c|}
\hline Material & $\begin{array}{c}\rho \\
\left(\mathrm{kg} . \mathrm{m}^{-3}\right)\end{array}$ & $\begin{array}{c}\mathrm{k} \\
\left(\mathrm{W} \cdot \mathrm{m}^{-1} \cdot{ }^{\circ} \mathrm{C}\right)\end{array}$ & $\begin{array}{c}\mathrm{C} \\
\left(\mathrm{kcal} . \mathrm{kg}^{-1} \cdot \mathrm{K}^{-1}\right)\end{array}$ & $\begin{array}{c}\mathrm{x} \\
(\mathrm{m})\end{array}$ & $\begin{array}{c}\Pi \\
\mathrm{g} / \mathrm{mhmmHg}\end{array}$ & $\omega$ \\
\hline SLB & 1817 & 0.887 & 0.27 & 0.15 & 0.07 & 0.029 \\
\hline SLBP & 1497 & 0.482 & 0.25 & 0.15 & 0.07 & 0.070 \\
\hline SLBS & 1451 & 0.396 & 0.24 & 0.15 & 0.07 & 0.052 \\
\hline Plaster & 892 & 0.19 & 0.40 & 0.02 & 0.0033 & 0.42 \\
\hline
\end{tabular}

$\omega$ : slope of the sorption isotherm

SLB: Stabilized lateritic brick

SLBP: Stabilized lateritic brick with incorporation of natural pozzolan

SLBS: Stabilized lateritic brick with incorporation of sawdust

The water content was determined from the experimental curves of sorption isotherms presented in Fig. 1. In this figure, experimental points were obtained for relative humidity up to $40 \%$ 
due to the meteorological conditions. To obtain water content for relative humidity less than $40 \%$, a model was developed.

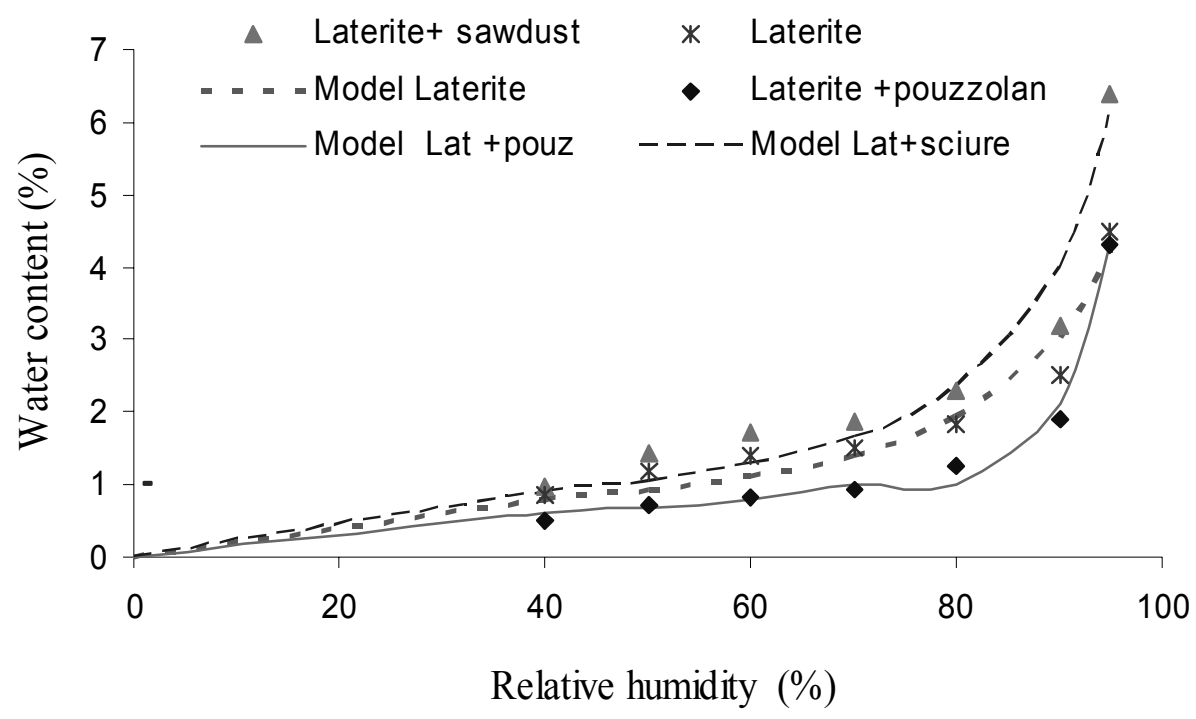

Fig. 1: Sorption isotherms of the three building materials

As the external surface of the building envelope is in contact with the climatic conditions, meteorological parameters (i.e. outside temperature $\mathrm{T}_{\infty}$ and outside relative humidity $\mathrm{RH}_{\infty}$ ) were also needed in the simulation. The external conditions were varied according to the data in Table 2. The room temperature and relative humidity are essential to achieve the computation. They were assumed to be constant throughout the year. The relative humidity $\left(\mathrm{RH}_{\mathrm{i}}=60 \%\right)$ and the temperature $\left(\mathrm{T}_{\mathrm{i}}=20^{\circ} \mathrm{C}\right)$ were chosen according to the thermal comfort conditions in tropical climate [9].

Table 2: External air conditions for the three climates considered.

\begin{tabular}{|l|l|l|l|l|l|l|l|l|l|l|l|l|l|}
\cline { 2 - 13 } \multicolumn{2}{c|}{} & Jan & Feb & Mar & Apr & May & Jun & Jul & Aug & Sept & Oct & Nov & Dec \\
\hline \multirow{3}{*}{ Dla } & $\mathrm{T}\left({ }^{\circ} \mathrm{C}\right)$ & 27.6 & 28.1 & 27.8 & 27.6 & 27.2 & 26.2 & 25.1 & 25.1 & 25.6 & 26.1 & 26.7 & 27.2 \\
\cline { 2 - 14 } & $\mathrm{h}(\%)$ & 79 & 78 & 80 & 81 & 82 & 84 & 87 & 88 & 85 & 84 & 82 & 81 \\
\hline \multirow{3}{*}{ Yde } & $\mathrm{T}\left({ }^{\circ} \mathrm{C}\right)$ & 24.4 & 25.3 & 25.0 & 24.6 & 24.1 & 23.4 & 22.6 & 22.6 & 23.1 & 23.3 & 23.7 & 23.7 \\
\cline { 2 - 13 } & $\mathrm{h}(\%)$ & 75 & 72 & 76 & 79 & 80 & 82 & 83 & 83 & 82 & 82 & 80 & 78 \\
\hline \multirow{2}{*}{ Gra } & $\mathrm{T}\left({ }^{\circ} \mathrm{C}\right)$ & 26.0 & 28.9 & 32.2 & 33.0 & 30.7 & 38.2 & 26.7 & 26.3 & 26.7 & 28.0 & 27.5 & 26.0 \\
\cline { 2 - 13 } & $\mathrm{h}(\%)$ & 31 & 26 & 29 & 47 & 63 & 74 & 79 & 81 & 80 & 72 & 52 & 38 \\
\hline
\end{tabular}

Dla $=$ Douala

$$
\text { Yde }=\text { Yaoundé } \quad \text { Gra }=\text { Garoua }
$$

The computer program HMtrans assumes that there is no thermal and hydric flux variation in the y direction, thus thermal flux $\Phi_{\mathrm{T}}$ and hydric flux $\Phi_{\mathrm{H}}$ were equal to zero at the floor and ceiling edges. Consequently, these flux were considered only in x direction (Fig. 2). 


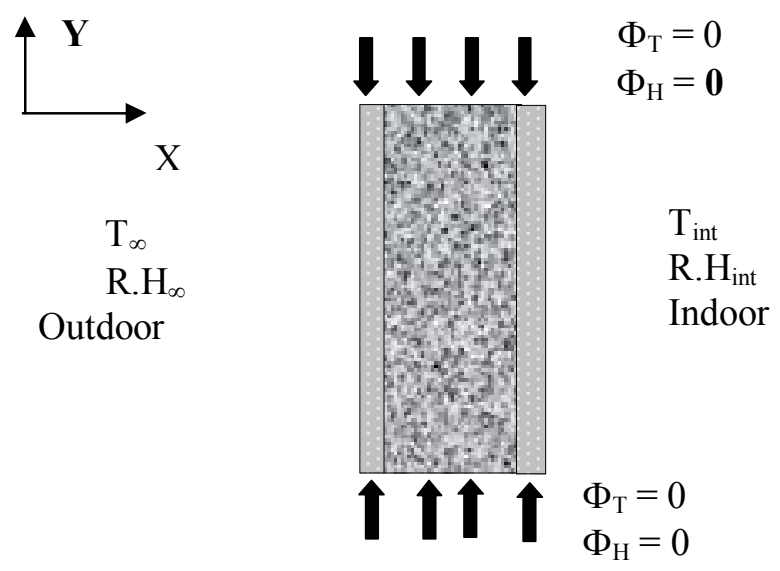

Fig. 2: Portion of building envelope considered by Fortran computer program HMTrans.

\section{Results and discussion}

The developed analysis was employed to investigate the hygrothermal behavior of the wall under the effect of two different environments i.e. indoor and outdoor atmospheres. In order for the building envelope to perform its role of separating interior and exterior environments, it must have structural integrity and durability. Of particular importance of all environmental conditions, moisture poses the biggest threat to integrity and durability, accounting for up to $80 \%$ of damage in building envelopes [10]

\subsection{Profiles of temperature, relative humidity and water content}

The computation model allows the calculation of temperature, relative humidity and water content distribution profiles throughout the building envelope. The monthly average temperature was considered for the calculation and the month chosen was the warmest in the year. An example of temperature profile for a composite wall is presented in Fig. 3. The variation of temperature for the uniform layer (plaster, lateritic soil brick and plaster) appears to be linear. 


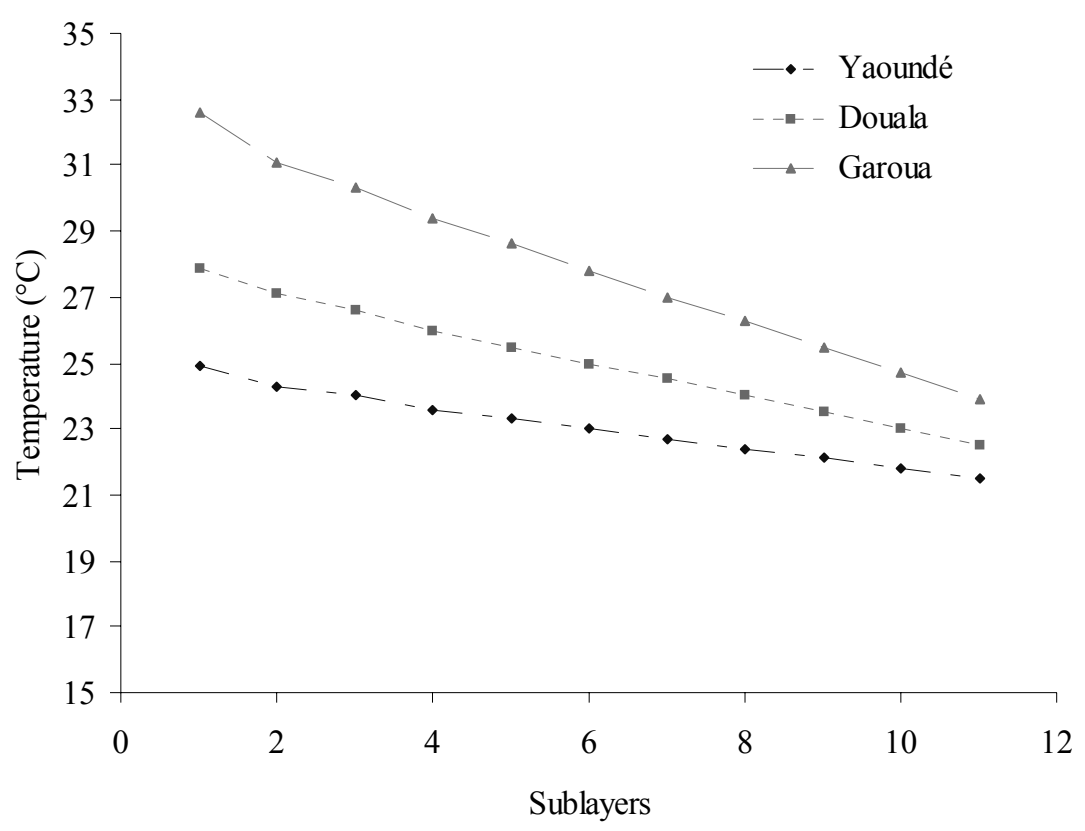

Fig. 3: Temperature profile within a lateritic soil brick building envelope

Fig. 4 shows the relative humidity profile throughout the wall for three different climates. It is observed that the relative humidity in the external wall remains constant for the two first sub-layers. The decrease of the relative humidity profile can be explained by the low indoor relative humidity $(60 \%)$ that has been chosen to satisfy the inhabitant's comfort.

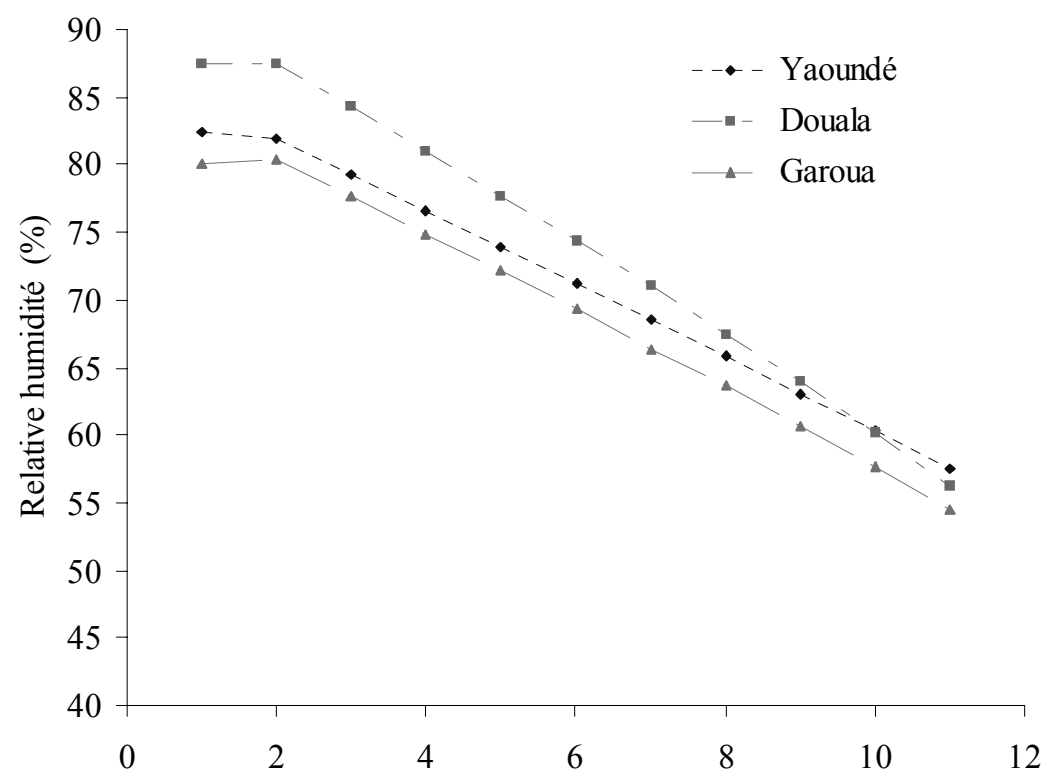

Fig. 4: Relative humidity profile within a lateritic soil brick building envelope 
The water content variation profiles throughout a SLB wall are presented in Fig. 5. They show that water content varies between $2.5 \%$ and $1.6 \%$. This allows concluding that there is minimum possibility of water condensation.

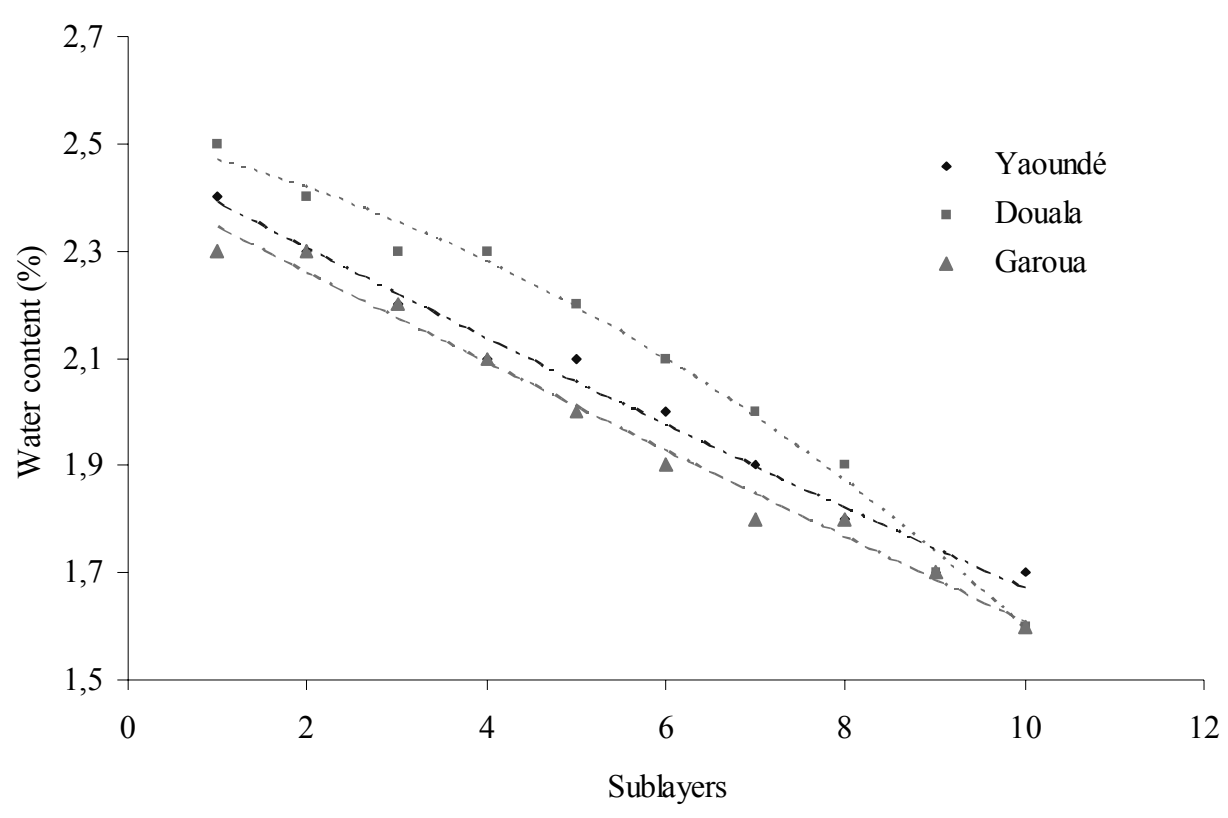

Fig. 5: Water content profile within composite building envelope

\subsection{Effect of plaster on the relative humidity, temperature and water content profiles}

Fig. 6 shows that the interior plaster on the surface of the wall modifies considerably the humidity profile. It is observed that the humidity profile of SLB is lower than that of SLBP and SLBS, which are respectively more porous material and more hygroscopic material than SLB. It can be observed in Fig. 10 that plaster on the outside of the wall contributes to maintain on the exterior surface of the building envelope at outdoor relative humidity and consequently to protect the building envelope from humidity.

The plaster layer also modifies the temperature profile within the wall as shown in Fig. 7. The modification of the slope of temperature profile is explained by the fact that thermal conductivity of lateritic soil brick is different from that of the plaster.

The plaster layers on the outside and inside surfaces of the wall create a discontinuity of the water content profile as it is shown in Fig. 8. The plaster protects earth blocks from humidity and contributes to their durability. 

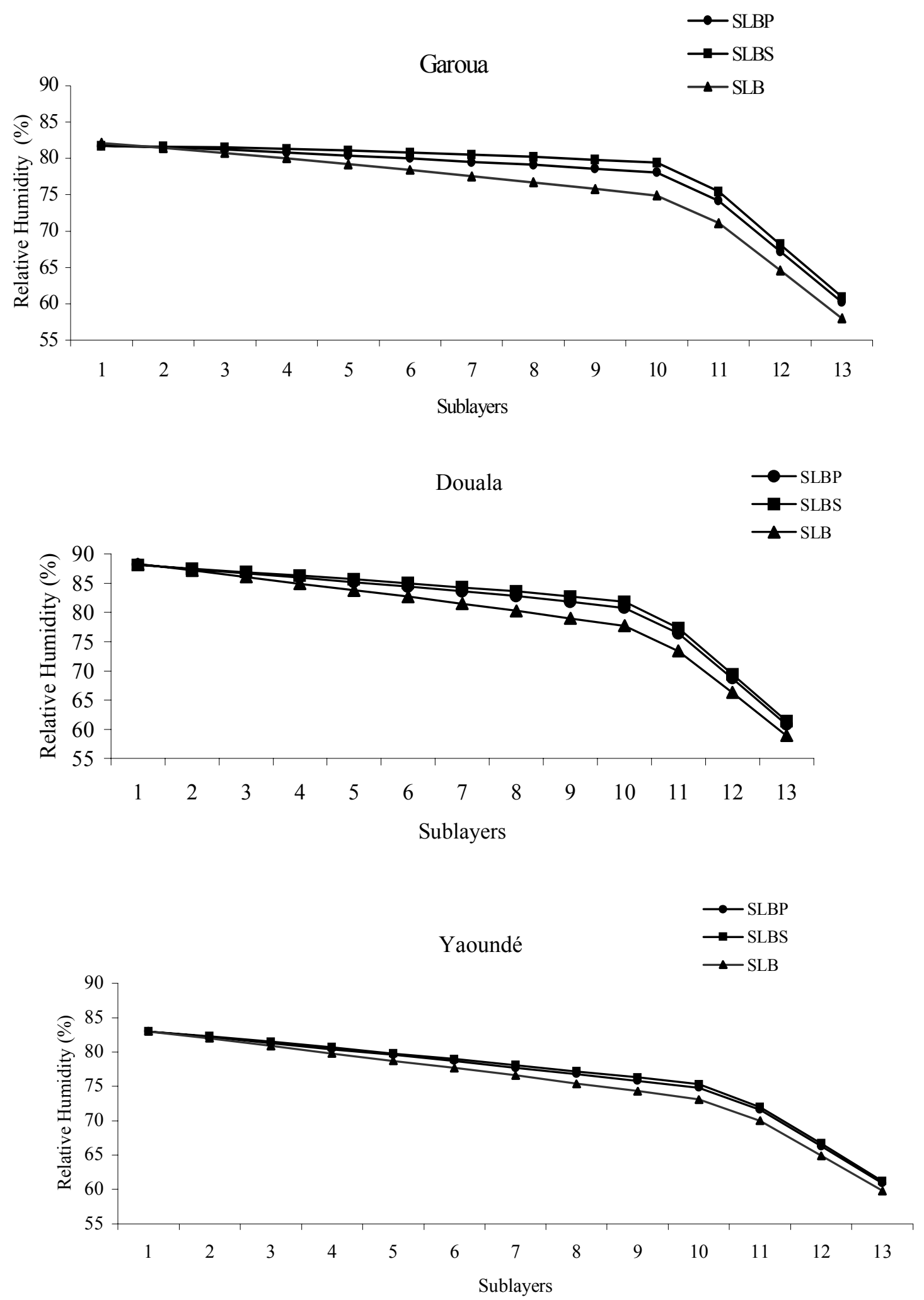

Fig.6: Influence of plaster on the relative humidity profile for different building envelope materials 

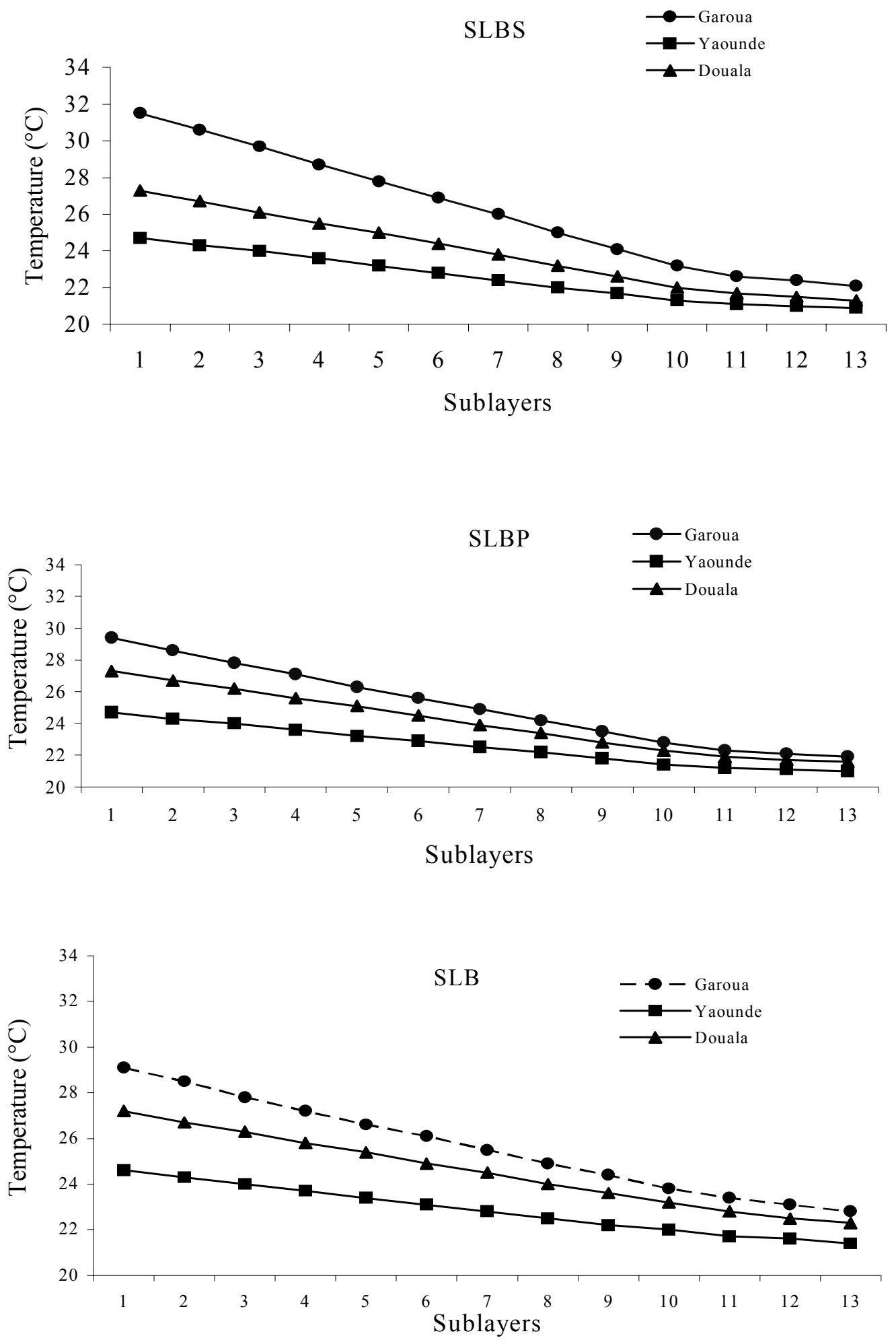

Fig.7: Influence of plaster on the temperature profile within building envelope for different climates 

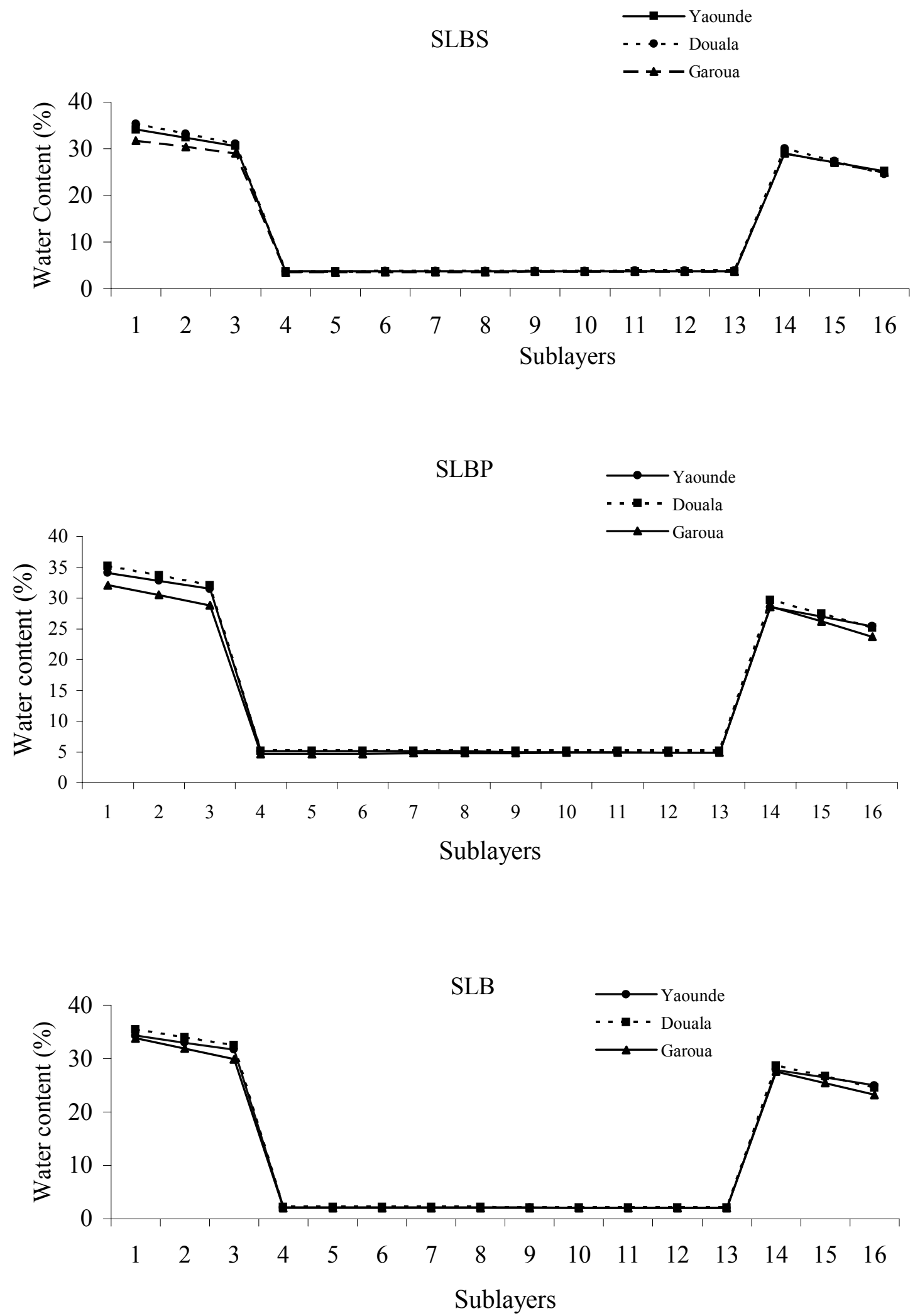

Fig. 8: Influence of plaster on water content profile within composite building envelope 
Fig. 9 shows the profiles of temperature with walls made of SLB, SLBP and SLBS. The slope of SLB profile is the smallest due to the fact that it has the greatest thermal conductivity. The decrease of these profiles is more rapid in Garoua because this locality has the highest outdoor temperature.

The relative humidity profiles within composite wall with plaster layer on outside and inside surfaces are presented in Fig. 10. It is observed that higher relative humidity is obtained with SLBS. It can be explained by the fact that incorporating sawdust in SLB gives a more hygroscopic material. The presence of natural pozzolan in SLBP increases the number of pores that contribute to increase the relative humidity in this material.

The Building material with incorporation of natural pozzolan (SLBP) presents the more important water content as it is shown in Fig. 11. In fact, this material is more porous than SLB and SLBS. The water content increases in this material because air in pores is progressively replaced by water vapor. 

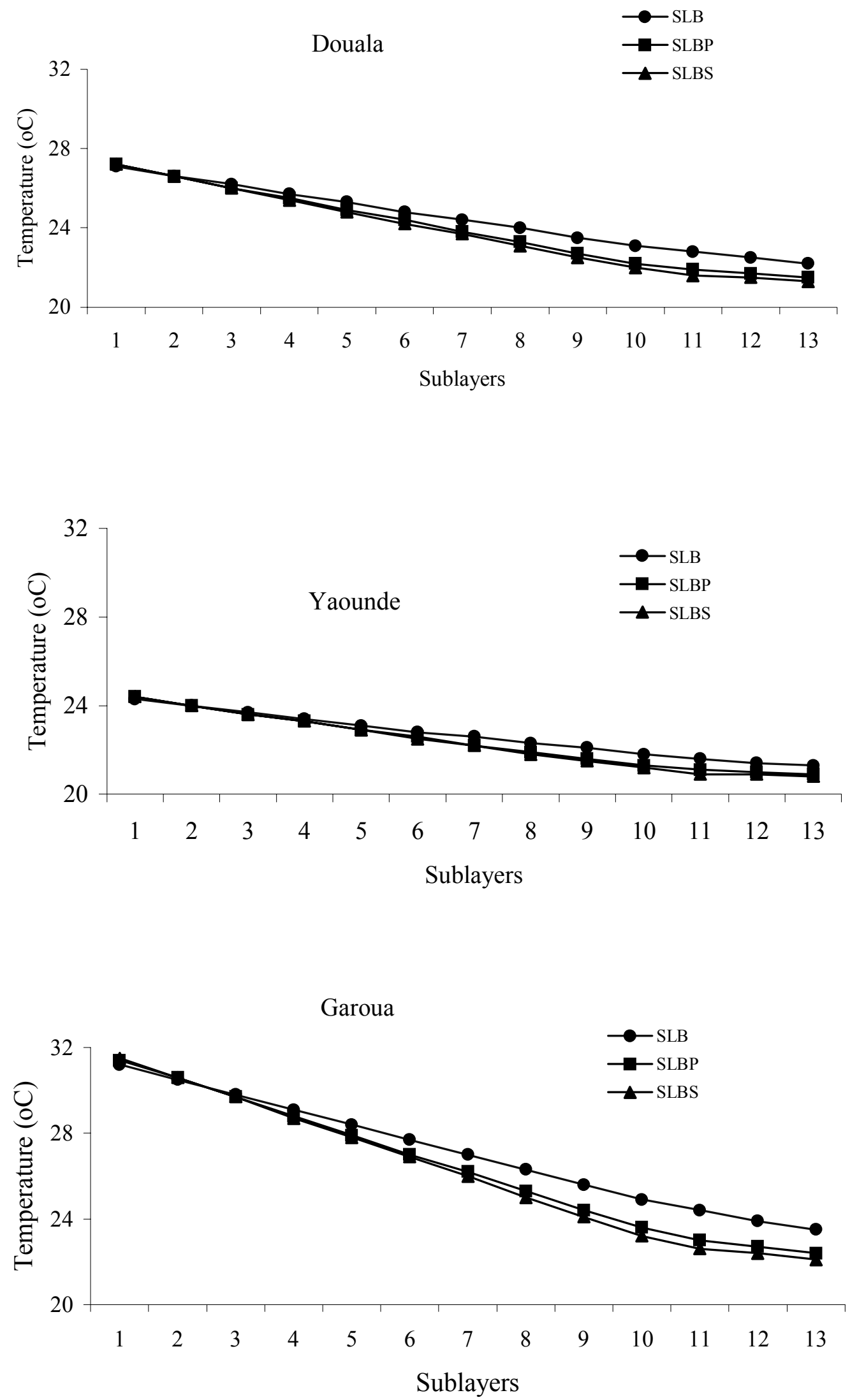

Fig.9: Effect of different building envelope materials on temperature profile 

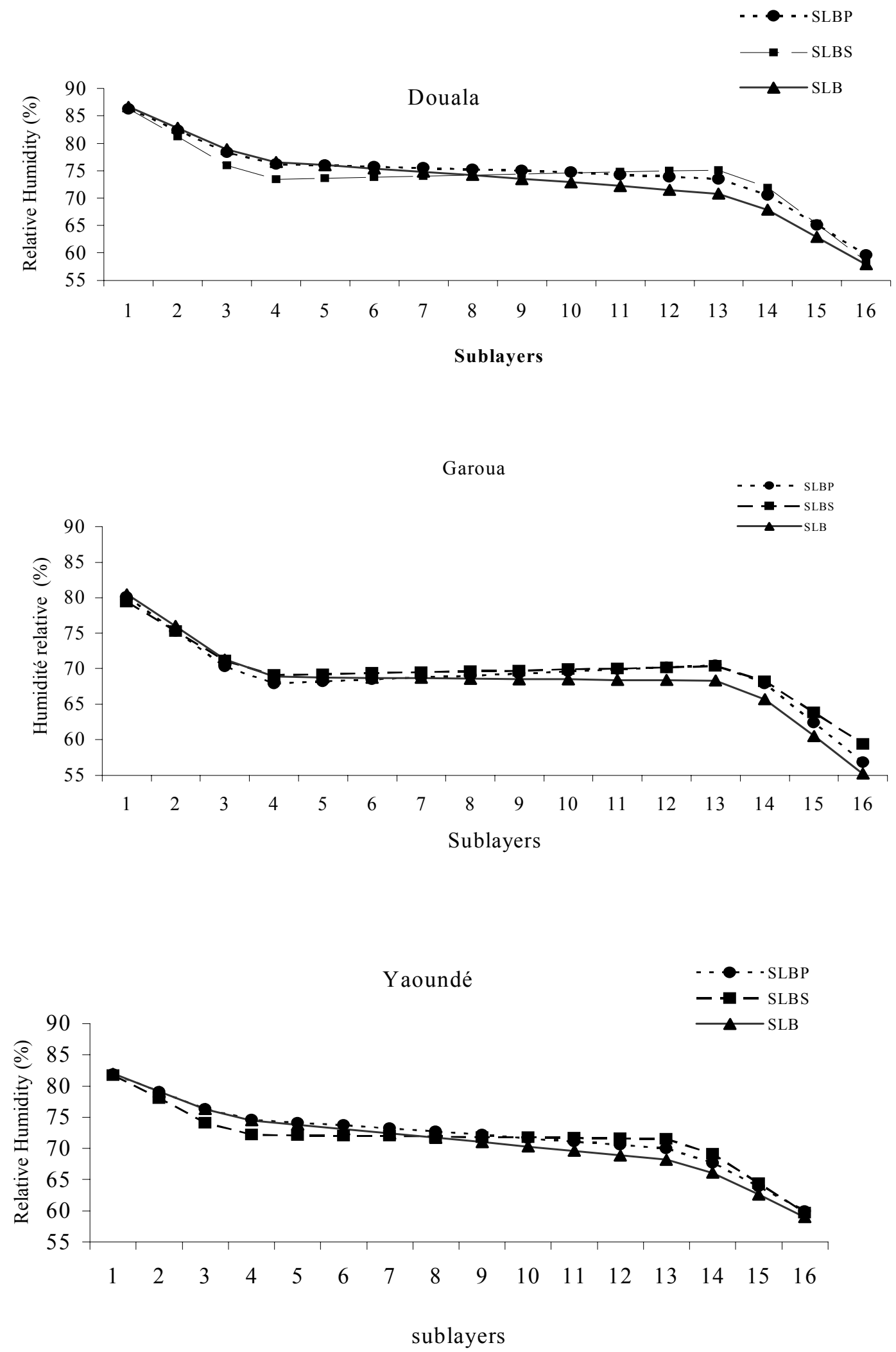

Fig. 10: Influence of material on relative humidity profile within building envelope 
Douala

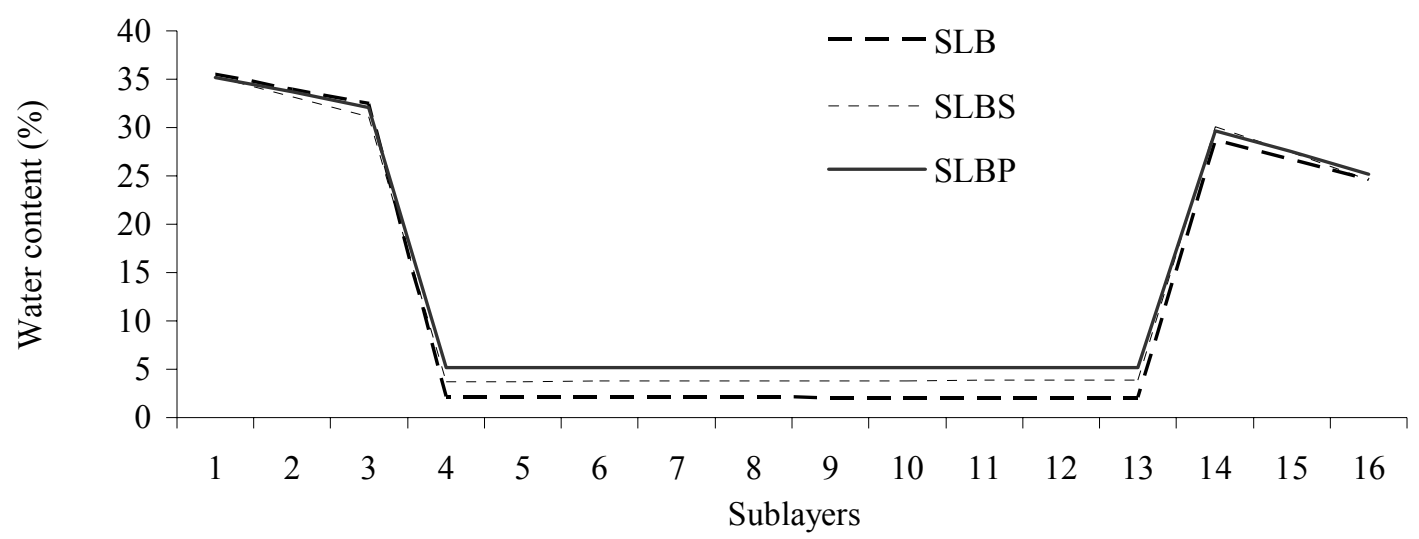

Yaoundé

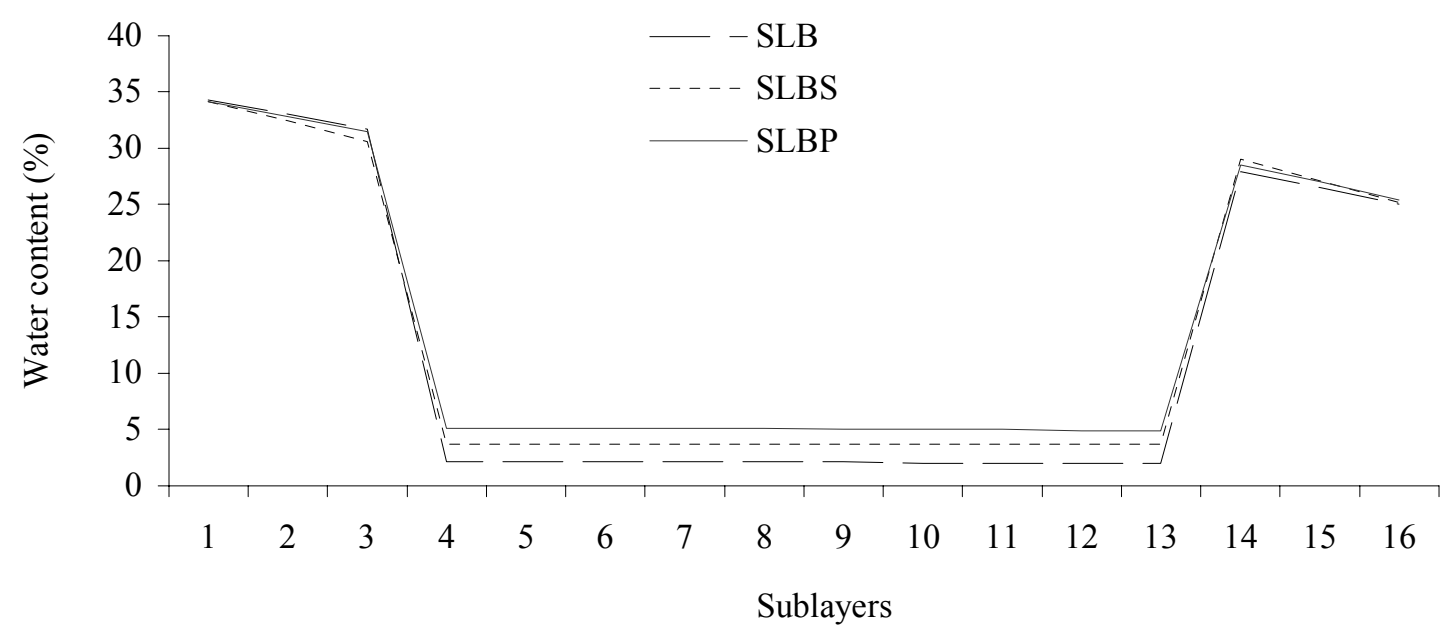

Garoua

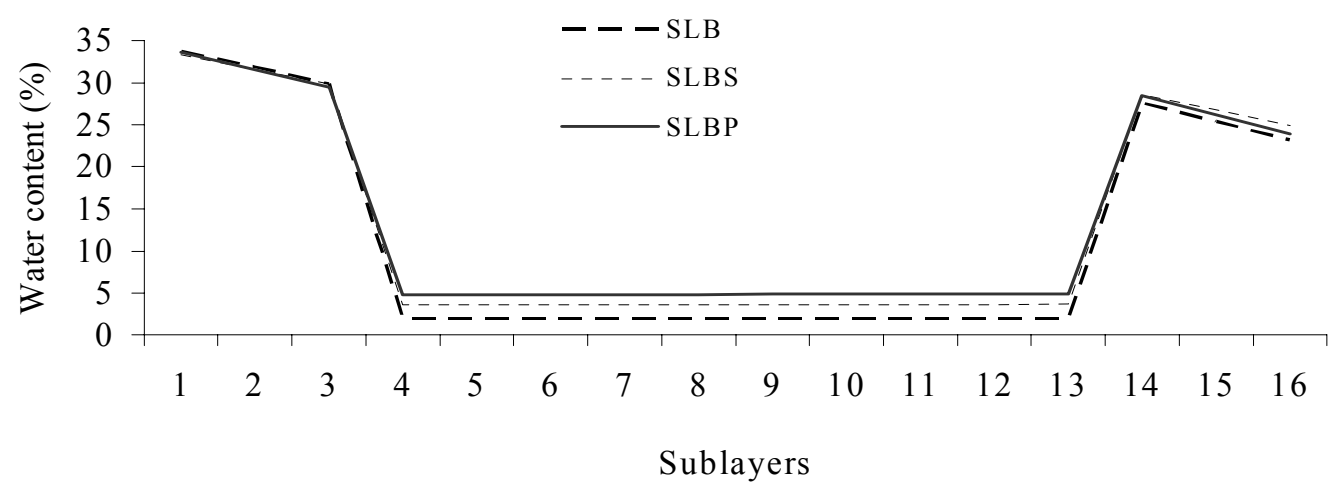

Fig. 11: Influence of material on water content profile within a composite building envelope 


\section{Conclusion}

The objective of this paper was to investigate the behavior of building envelope made of local materials, under the effect of tropical and equatorial climates. Walls were made with lateritic soil bricks, and lateritic soil bricks with incorporation of natural pozzolan or sawdust. The numerical study has been performed by modeling and simulation of simultaneous heat and moisture transfers with HMTrans simulation program. To predict the performance of local building materials exposed to different climates (indoor and outdoor temperature and relative humidity), thermal and transport properties were investigated. Thermal and hydric properties of materials were determined experimentally. Computer simulation tests permitted the determination of temperature, relative humidity and water content profiles in building envelopes made of the tested local materials. The results allow the prediction of the duration of the exposed building walls to the local weather conditions. They show that for any of the three climatic conditions considered, relative humidity and water content do not exceed $87 \%$ and $35 \%$ respectively. There is therefore minimum possibility of water condensation in the building envelope materials studied. It can be concluded that lateritic soil bricks with incorporation of natural pozzolan or sawdust can be used as building envelopes in tropical and equatorial regions. Their durability is not strongly affected by the climatic conditions in these regions.

\section{Acknowledgements}

Part of this work was done within the framework of the Associateship Scheme of the Abdus Salam International Centre for Theoretical Physics, Trieste, Italy.

The author is very grateful to the Swedish International Development Cooperation Agency (SIDA) for financial support. 


\section{References}

1. Hens H. Heat and moisture transfer in highly insulated envelope parts, task 1: modelling. Final Report, International Energy Agency, Annex 24,vol. 1, Catholic University, Leuven, Belgium, 1996.

2. P.T. Tsilingiris On the transient thermal behaviour of structural walls---the combined effect of time varying solar radiation and ambient temperature. Renewable Energy 27 (2002) 319-336.

3. A.N. Noumowe, T. Ohkudo, M. Makatayma and K. Watanabe. Coupling Heat and mass transfers in building. 8th International conference on durability of building materials and components. May 20-June 3, 1999 Vancouver, Canada.

4. Gawin Dariusz. Thermo-hydro-mechanical analysis of partially saturated porous materials. Engineering Computations vol. 13 No 7 1996, pp 113-143.

5. Shengwei Wang, Youming Chen. Transient heat flow calculation for multilayer constructions using a frequency domain regression method. Building and environment 38 (2003) 45-61.

6. P. Meukam, A. Noumowe, Y. Jannot and R. Duval. Thermophysical and mechanical characterization of stabilized clay bricks for building insulation, in press in Materials and Structures/Matériaux et Constructions.

7. Watanabe Kazumasa. Hygro-thermal condition in building Components simulated with heat and moisture simultaneous transfer model. March 1994.

8. Sanders C. Condensation effects on structure durability. Building Services: cibse Journal, 1988.

9. IEPF (Institut de l'énergie et de l'environnement de la francophonie), Coordonnateur. Efficacite énergétique de la climatisation en région tropical. Tome1, 2002.

10. Bomberg M.T. and Brown W.C. Building Envelope and Environmental Control: Part 1-Heat, Air and Moisture interactions. Construction Canada 35 (1), 1993, p15-18. 